significant trends over time in average daily intake of either energy or fat, determined by weighing food intake for seven days.

\section{Comment}

Our study helps to resolve the uncertainty over the amount and type of exercise needed to diminish the risk of coronary heart disease. In these sedentary women a considerable progressive increase in high density lipoprotein cholesterol concentration resulted from a programme of brisk walking for one year.

What are the implications of these changes in blood lipid concentrations for the risk of coronary heart disease? Three studies evaluated prospectively the association between high density lipoprotein cholesterol concentration and subsequent coronary heart disease in women. ${ }^{24}$ Each reported the concentration to be a strong, negative, independent predictor, an increase of $0.26 \mathrm{mmol} / \mathrm{l}(10 \mathrm{mg} / 100 \mathrm{ml})$ being associated with a $42-50 \%$ decrease in risk. ${ }^{34}$ Based on this evidence, a $54-64 \%$ reduction in the number of coronary events over 10 years would be expected if the changes shown here were achieved in a population of women. The importance of our findings is further emphasised by the considerable favourable changes in the ratio of total cholesterol to high density lipoprotein cholesterol concentrations. This ratio was highly predictive of coronary heart disease in Israeli women, independent of the total cholesterol concentration.

Total cholesterol concentration did not change significantly in the walkers compared with the controls. Nevertheless, at 12 months the mean value was $0.35 \mathrm{mmol} / \mathrm{l}$ lower than the baseline value; it had tended to decrease most in those with the highest baseline values. Consequently there might be a therapeutic role for low intensity exercise in patients with hypercholesterolaemia.

Exercise will play a part in a population approach to coronary heart disease only if the amount and intensity of exercise needed to confer a decrease in risk are attainable and attractive for large numbers of people. In women high density lipoprotein cholesterol concentration is arguably the most important lipid risk factor. ${ }^{5}$ We found that it can be modified by a socially acceptable exercise regimen.

We thank Dr Carol Jagger, department of community medicine, Leicester Medical School, for statistical advice.

1 Hardman AE, Hudson A, Jones PRM, Norgan NG. Brisk walking influence he physiological respinses to a submaximal step test in women. 7 Physiol 1989;409:22P.

2 Bush TL, Criqui MH, Cowan LD, et al. Cardiovascular disease mortality in women; results from the Lipid Research Clinics follow-up study. In: Eake ED, Packard B, Wenger NK, Clarkson TB, Tyroler HA, eds. Coronary hear disease in women. New York: Haymarket Doyma, 1987:106-11.

3 Kannel WB. Metabolic risk factors for coronary heart disease in women perspective from the Framingham study. Am Heart f 1987;114:413-9.

4 Brunner D, Weisbort J, Meshulam N, et al. Relation of serum total cholestero and high-density lipoprotein cholesterol percentage to the incidence of definite coronary events: twenty-year follow-up of the Donolo-Tel Aviv prospective coronary artery disease study. Am $\mathcal{f}$ Cardiol 1987:59:1271-6.

Bush TL, Fried LP, Barrett-Connor E Cholesterol, lipoproteins, and coronary heart disease in women. Clin Chem 1988;34:B60-70.

(Accepted 25 August 1989)

\title{
Effect of nifedipine on Doppler flow velocity waveforms in severe pre-eclampsia
}

\author{
Kevin P Hanretty, Martin J Whittle, \\ Catherine A Howie, Peter C Rubin
}

Departments of Midwifery and Materia Medica, University of Glasgow, Glasgow

Kevin P Hanretty, MRCOG, Wellcome Trust surgical training fellow

Martin J Whittle, FRCOG, consultant obstetrician Catherine A Howie, BSC, statistician

University Hospital Nottingham NG7 2UH Peter C Rubin, FRCP professor of therapeutics

Correspondence to: Professor Rubin.

BrMed f 1989;299:1205-6
Blood pressure is hard to control in women with pre-eclampsia. Even when a successful drug regimen is found there is concern about the possible effects of reducing blood pressure on perfusion to the fetoplacental unit. We recently showed that the combination of atenolol and nifedipine can usefully prolong pregnancies complicated by pre-eclampsia.' Although many data suggest that atenolol can safely be used in the third trimester, ${ }^{2}$ the safety of nifedipine has not been fully investigated. Lindow et al recently reported that nifedipine does not reduce uteroplacental blood flow as measured with a radioisotope technique. No data exist, however, on haemodynamic variables on the fetal side of the circulation. We report here the measurement by Doppler ultrasonography of variables of blood velocity on both the maternal and fetal sides of the circulation in women who had received nifedipine as monotherapy in pre-eclampsia.

\section{Patients, methods, and results}

We studied nine women with hypertension and proteinuria who had been normotensive in early pregnancy and had normal Doppler waveform variables. Their mean age was 28.0 (SD 5.5) years, and eight were primigravidas. The gestation at the time of study was $29 \cdot 4$ weeks (range $24-35$ weeks). A $4 \mathrm{MHz}$ continuous wave Doppler system with a spectrum analyser was used to obtain five representative waveforms from the uteroplacental and umbilical arteries after the patients had rested in the semirecumbent position for 30 minutes. The technique has been described previously. ${ }^{4}$ The pulsatility index (systolic minus diastolic velocity/mean velocity), an index of downstream impedance to flow, was calculated individually for each waveform and the mean recorded. Blood pressure was measured with an automatic sphygmomanometer. Maternal pulse and fetal heart rate were also noted. Nifedipine retard $20 \mathrm{mg}$ was then given orally and all recordings repeated hourly for eight hours. Differences in the variables studied were analysed by repeated measures analysis of variance with Bonferroni multiple comparisons when appropriate.

Despite a rapid and sustained effect on blood pressure no effect was seen on either fetal or maternal Doppler variables (table). The reduction in systolic blood pressure was significant for the first six hours after treatment, and an effect on diastolic blood

Mean $(S D)$ values of Doppler variables of blood flow after administration of nifedipine retard $20 \mathrm{mg}$ to nine women with pre-eclampsia

\begin{tabular}{|c|c|c|c|c|c|c|c|c|c|c|}
\hline & \multicolumn{10}{|c|}{ Time (hours) after nifedipine was given } \\
\hline & 0 & 1 & 2 & 3 & 4 & 5 & 6 & 7 & 8 & Significance \\
\hline \multicolumn{11}{|l|}{ Blood pressure $(\mathrm{mm} \mathrm{Hg})$ : } \\
\hline Systolic & $157(18)$ & $142(9)$ & $141(13)$ & $143(9)$ & $148(14)$ & $146(14)$ & $146(9)$ & $154(19)$ & $153(13)$ & $\mathrm{p}=0.022$ \\
\hline Diastolic & $99(9)$ & $85(5)$ & $84(6)$ & $84(7)$ & $85(7)$ & $86(7)$ & $89(9)$ & $91(11)$ & $90(10)$ & $\mathrm{p}<0.001$ \\
\hline Fetal heart rate (beats/min) & $143(7)$ & $145(11)$ & $142(10)$ & $143(9)$ & $140(10)$ & $142(11)$ & $140(7)$ & $141(9)$ & $139(7)$ & $\mathrm{p}=0.878$ \\
\hline \multicolumn{11}{|l|}{ Pulsatility index: } \\
\hline Umbilical artery & $1.73(0.61)$ & $1.85(0.73)$ & $1.90(0.57)$ & $1.81(0.55)$ & $1.86(0.55)$ & $1.87(0.50)$ & $1.73(0.49)$ & $1.82(0.49)$ & $1 \cdot 78(0 \cdot 45)$ & $\mathrm{p}=0.848$ \\
\hline Uteroplacental artery & $1.20(0.60)$ & $1.24(0.80)$ & $1.22(0.85)$ & $1.41(1.05)$ & $1 \cdot 35(1 \cdot 10)$ & $1.31(0.88)$ & $1 \cdot 26(0 \cdot 80)$ & $1 \cdot 22(0 \cdot 83)$ & $1 \cdot 20(0 \cdot 84)$ & $\mathrm{p}=0.871$ \\
\hline
\end{tabular}


pressure was seen throughout the study. No effect was seen on fetal heart rate.

\section{Comment}

The efficacy of oral calcium antagonists in controlling blood pressure makes their use attractive in preeclampsia. As experience with nifedipine has been based largely on its value as a second line agent in pregnancies that are already severely compromised, however, assessment of its possible adverse effects is difficult as the outcome in these pregnancies is often poor. The results of this study suggest that, when the Doppler waveform variables are normal, nifedipine can lower blood pressure in women with pre-eclampsia without compromising blood flow in the fetus. Further studies are needed to assess the consequences of lowering blood pressure with this and other drugs in patients in whom the Doppler variables are abnormal.

This work was supported by the Wellcome Trust.

Rubin PC, Butters L, McCabe R. Nifedipine and platelets in pre-eclampsia. Am $\mathcal{f}$ Hypertens 1988;1:175-8.

2 Rubin P, Butters L, Clark D, et al. Placebo controlled trial of atenolol in the treatment of pregnancy associated hypertension. Lancet 1983;i:431-4.

3 Lindow SW, Davies N, Davey DA, Smith JA. The effect of sublingua nifedipine on uteroplacental blood flow in hypertensive pregnancy. $\mathrm{Br} \mathscr{f}$ Obstet Gynaecol 1988;95:1276-8

4 Hanretty K, Whittle M, Rubin PC. Doppler uteroplacental waveform in pregnancy induced hypertension: a reappraisal. Lancet 1988;i:850-2.

(Accepted 14 August 1989)

\section{Regional variations in policy on exposing women of childbearing age to ionising radiation}

\section{I Wise, R J Cherry}

East Birmingham Hospital, Birmingham D I Wise, FRCS, orthopaedic registrar

R J Cherry, FRCS, orthopaedic consultant

Correspondence to:

Mr D I Wise, Department of

Orthopaedics, Bradford

Royal Infirmary, Bradford

BD9 6RJ.

BrMed f 1989;299:1206

Women and their doctors often experience frustration because radiological examinations are postponed because of the potential risk to a fetus. Junior doctors find that the policy varies from region to region for routine procedures. We carried out a survey to find out how local policies differ despite the existence of a national policy.

\section{Methods and results}

Fifty hospitals were selected as a sample. One regional referral hospital was selected in each of the 16 regions in England, Scotland, and Wales and at least one other district general hospital was selected at random from each region. We contacted the superintendent radiographer in each hospital either in person by telephone or by a printed returnable letter. We asked whether they followed a 10 day rule, a 28 day rule, or another policy on irradiating the pelvis and abdomen in women of childbearing age.

We received replies from all 50 hospitals; one refused to give information relevant to the study. Twenty four followed a strict 28 day rule, 10 followed a 10 day rule, seven required the patient to sign a consent form saying that to the best of their knowledge they were not pregnant, and three displayed notices in the radiology department asking patients to tell the radiographer whether they were pregnant. All the hospitals used a 28 day rule with good screening and collimation for radiography of the head and neck, chest, arms, and legs.

\section{Comment}

In 1952 Russell and Russell suggested that radiation caused damage to the development of mouse embryos. The results of this and other research prompted the International Commission on Radiological Protection to recommend that "all radiological examinations of the lower abdomen and pelvis of women of reproductive capacity that are not of importance in connection with the immediate illness of the patient be limited in time to the period when pregnancy is improbable (the 10 day interval following the onset of menstruation)." This became the so called " 10 day rule."
Recently it was suggested that this rule is unnecessarily restrictive. Russell summarised the arguments against a 10 day rule. ${ }^{3}$ Firstly, organogenesis of human embryos does not start until the third week after conception. Unless a menstrual period has been missed, it is unnecessary to avoid irradiation. Secondly, there is no evidence that irradiating a fetus in the early weeks of pregnancy is more dangerous than irradiating the ovum in the weeks before fertilisation. ${ }^{4}$ Thirdly, the worst estimates would predict one extra case of abnormality in 30 years. Finally, the cost of implementing the 10 day rule appears to be a hundred times greater than any possible benefit.

The International Commission on Radiological Protection withdrew its support of the 10 day rule in 1984 , suggesting that no special limitation was needed on exposures required within four weeks from the onset of menstruation. ${ }^{5}$ The National Radiological Protection Board followed in 1985 and adopted the "28 day rule."

Though the National Radiological Protection Board issued these guidelines over three years ago, the results of our survey suggest that a fifth of hospitals in our sample of 50 have not yet changed their policy. This is costly to the National Health Service and causes inconvenience to patients. In a few hospitals notices were displayed in the radiography department asking patients to tell doctors that they were pregnant. But this method will not reach people who cannot read English or whose vision is poor.

We ask whether this variation in policy is an example of clinical freedom, or whether national recommendations should be enforced, perhaps by statute. Do some radiology departments not trust the recommendations of the International Commission on Radiological Protection or are they just being overcautious?

1 Russell LB, Russell WL. Radiation hazards to the embryo and fetus. Radiology 1952;58:369-76.

2 International Commission on Radiological Protection. Code of practice for the protection of persons against ionizing radiation arising from medical and dental use. protection of perso 1972 .

3 Russell JG. The rise and fall of the ten day rule. Br 7 Radiol 1986:59:3-6.

4 Anonymous. Antenatal ionising radiation and cancer [Editorial]. Lance 1988;i:448-9.

5 International Commission on Radiological Protection. Statement from the Washington meeting. Oxford: Pergamon Press, 1984.

(Accepted 7 August 1989)

\section{Correction}

Prevalence of antibody indicating Lyme disease in farmers in Wigtownshire

An editorial error occurred in this article by Dr A G Baird and others (30 September, p 836). In the first sentence of the third paragraph in the patients, methods, and results section "Listeria monocytogenes" should have read "infectious mononucleosis." 